\title{
Burnout em Professores Universitários: Impacto de Percepções de Justiça e Comprometimento Afetivo ${ }^{1}$
}

\author{
Ivone Félix de Sousa ${ }^{2}$ \\ Helenides Mendonça \\ Pontifícia Universidade Católica de Goiás
}

\begin{abstract}
RESUMO - Esta pesquisa objetivou analisar o poder mediacional do comprometimento organizacional afetivo na relação entre as percepções de justiça distributiva, processual e interacional e o burnout. Participaram da pesquisa 233 professores universitários. Foram aplicados os instrumentos avaliativos Maslach Burnout Inventory, Escala de Percepção de Justiça Organizacional e Organizational Commitment Questionnaire. Analisou-se o poder mediacional do comprometimento na relação entre a percepção de justiça e o burnout, a partir da regressão hierárquica. O poder mediacional do comprometimento se confirmou na relação entre percepção de justiça distributiva e exaustão. Concluiu-se que a percepção de injustiça na forma de distribuição de recursos pode levar o professor universitário à exaustão, o que pode ter probabilidade aumentada diante da falta de comprometimento.
\end{abstract}

Palavras-chave: burnout; justiça organizacional; comprometimento organizacional afetivo.

\section{Burnout among University Professors: Impact of Justice Perceptions and Affective Commitment}

\begin{abstract}
This study aimed to analyze the mediational power of the affective organizational commitment in the relation among the perceptions of distributive, procedural, and interactional justice and burnout. Participants were 233 university professors. The following instruments were used: Maslach Burnout Inventory, Organizational Justice Perception Scale, and Organizational Commitment Questionnaire. We analyzed the mediational power of commitment in the relation between perception of justice and burnout, from a hierarchical regression. The mediational power of commitment was confirmed in the relationship between the perceptions of distributive justice and exhaustion. It can be concluded that the perceptions of injustice in the form of resource distribution may lead university professors to exhaustion, which might be more likely to happen if there is lack of commitment.
\end{abstract}

Keywords: burnout; organizational justice; affective organizational commitment.

A síndrome de burnout se apresenta como um dos grandes problemas psicossociais que afetam a qualidade de vida das pessoas e, por conseguinte, de profissionais das mais diversas áreas. O interesse e a preocupação pelo tema decorrem da severidade das consequências, tanto individuais, quanto organizacionais, acarretadas por esta síndrome, especialmente quando interfere nas relações interpessoais do profissional e em suas atividades laborais.

Este estudo investigou essa problemática em professores universitários por ser a docência uma atividade intelectual que exige inovações constantes. O mundo competitivo contemporâneo impõe o comprometimento dos professores com a organização em que atuam, de tal sorte que sejam capazes de lidar com novas formas didáticas de ensino que acompanhem o dinâmico mercado de trabalho. Questões como as exigências de qualificação dos profissionais de ensino, estabelecidas pelo Ministério da Educação, e o crescente número de universidades nos grandes centros, como na Região Centro-Oeste do Brasil, têm aumentado ainda mais

1 Pesquisa financiada pela Coordenação de Aperfeiçoamento de Pessoal de Nível Superior (CAPES/PROSUP) - 2006

2 Endereço para correspondência: SB 14, Qd. 19, Lt. 08, Portal do Sol I Goiânia, GO. CEP 74884-600. Fone: (62) 3275-3230. Fax: (62) 39461021.E-mail: helenides@uol.com.br e ivonefelixs@yahoo.com.br. as exigências em relação ao aprimoramento intelectual e à qualidade de trabalho desses profissionais.

Percebe-se, portanto, que essa profissão está ligada a fatores estressantes que abarcam aspectos objetivos, subjetivos e sociais. Durante o exercício de sua função, o profissional docente lida diretamente com outras pessoas e constantemente enfrenta problemas relativos a alunos, questões sociopolíticas e assistencialistas, além de dificuldades econômicas (Codo \& Vasques-Menezes, 2000). O baixo investimento em educação frequentemente coloca o professor em situação de conflito, pois além de perceber baixo salário, necessita empregar parte substancial dele em materiais didáticos para o aprimoramento de suas aulas.

Para acompanhar as exigências do mercado altamente competitivo, além de organizar as atividades relacionadas à educação propriamente dita, as atividades extracurriculares e os materiais da escola, o professor também precisa atuar na parte administrativa de planejamento e reciclagem, em atividades investigativas e de orientação, entre outras (Carlotto \& Palazzo, 2006). Porém, no momento em que poderia participar de decisões institucionais e reestruturação curricular, isto é, dos aspectos estruturais de seu trabalho, ele é apartado do processo, fato que tende a gerar conflitos que podem levá-lo ao adoecimento. Assim sendo, diversos auto- 
res têm se dedicado a entender as variáveis que contribuem para o desenvolvimento do burnout.

Carlotto e Câmara (2008) fizeram um levantamento das pesquisas brasileiras, em diversas áreas, com profissionais da saúde e educação, policiais, bombeiros e estudantes, e constataram que a categoria de professor é a que apresenta o segundo maior desenvolvimento da síndrome de burnout. Sabanc1 (2009) assevera que o burnout afeta a saúde da escola de forma significativa e todos esses achados demonstram a importância do desenvolvimento de estudos mais complexos envolvendo a variável burnout.

Diante da complexidade que envolve o trabalho do professor universitário, faz-se necessário compreender os fenômenos que permeiam a saúde dos docentes. Para tanto, a presente pesquisa dedicou-se a analisar o construto burnout de maneira integrada, considerando a multiplicidade de fatores a ele relacionados, com a intenção de ampliar as perspectivas teóricas sobre as variáveis antecedentes e mediadoras que levam os professores a desenvolver a síndrome de burnout.

Este estudo foi desenvolvido com o objetivo de analisar o poder mediacional do comprometimento organizacional afetivo na relação entre percepção de justiça e burnout. Nessa perspectiva, este trabalho apresenta a compreensão do modelo teórico adotado tanto para verificar se há relação entre a variável antecedente 'percepção da justiça organizacional' e burnout quanto para investigar se a variável 'comprometimento afetivo’ medeia esta relação.

O burnout resulta de prolongado processo de tentativas de lidar com determinadas condições de estresse sem lograr sucesso. A síndrome de burnout, diferentemente das reações agudas do estresse que se desenvolvem em resposta a incidentes críticos específicos, é uma reação a fontes de estresse ocupacional contínuas que se acumulam (Sousa \& Mendonça, 2006). Quando se fala em burnout, a ênfase recai não apenas nas reações físicas, mas também no processo de desgaste psicológico e nas consequências psicológicas e sociais da exposição crônica (Maslach, 2006).

A síndrome de burnout, que deixa o profissional sem ânimo e apático, não pode ser associada a qualquer realidade social, cultura ou país. Atualmente, apresenta-se como uma epidemia organizacional que predomina na educação e no sistema de saúde, atingindo não apenas professores e médicos, mas o conjunto de profissionais envolvidos com as instituições de ensino e de saúde (Codo, 1999). O trabalho deixa de ser empolgante e perde o sentido e o laborador que se envolve de forma afetiva com seus clientes ou alunos se desgasta, chegando ao extremo de desistir de suas atribuições (Maslach \& Jackson, 1981).

Entretanto, neste artigo, o burnout não é concebido tão somente como um problema pessoal, mas do ambiente social em que o trabalhador está inserido (Maslach, 2006). A estrutura e o funcionamento do local de trabalho ditam as formas pelas quais as pessoas interagem e como elas realizam suas tarefas. Quando os empreendedores não são capazes de reconhecer o lado humano do trabalho e quando existem grandes incompatibilidades entre as tarefas exigidas pela organização e a habilidade e/ou potencialidade do trabalhador para fazê-las, aumenta o risco de ocorrência de burnout.
Ao se constatar que o momento atual vem exigindo mudanças de paradigmas e métodos, percebe-se o burnout como consequência da demanda dessa nova postura. Não se trata de um fenômeno isolado ou que tampouco possa ser explicado como tal, mas que o burnout deve ser concebido como um desgaste psicológico advindo de processos que inserem as relações inter e intrapessoais em ambiente hostil de trabalho no qual o empregado está inserido (Maslach, 2006; Sousa \& Mendonça, 2006).

\section{A Síndrome de Burnout e suas Dimensões}

De acordo com a literatura pesquisada, o burnout é apresentado como uma variável que se configura em três dimensões: exaustão emocional, despersonalização ou cinismo e diminuição da realização pessoal ou ineficácia (Codo, 1999; Codo \& Vasques-Menezes, 2000; Maslach, 2006; Maslach \& Jackson, 1981; Monteiro, 2000; Tamayo \& Tróccoli, 2002a). Tamayo e Tróccoli (2002a) relatam que as perspectivas que antecedem o burnout surgem de maneira sequencial, estão distribuídas nessas três dimensões e, além disso, estão ligadas às condições de trabalho, às realizações pessoais, à injustiça organizacional e à autoavaliação.

Na concepção de Maslach (2006), a exaustão emocional está relacionada a aspectos individuais e, assim, o estresse individual configura-se como componente básico para a compreensão do burnout. Essa dimensão refere-se à sensação de que os problemas que causam o estresse extrapolam a capacidade do indivíduo e estão exaurindo seus recursos emocionais e físicos. Os principais antecedentes dessa dimensão são a sobrecarga de trabalho e o conflito intrapessoal.

A dimensão da despersonalização ou cinismo representa um componente que se refere ao contexto interpessoal do burnout e à reação negativa, indiferente ou excessivamente distanciada que o trabalhador estabelece com os diversos aspectos do trabalho. Essa dimensão geralmente desenvolve-se como proteção à exaustão emocional, à guisa de amortecedor emocional de preocupação desligada. O desligamento, por sua vez, pode desencadear a perda do idealismo e a desumanização dos outros. A evolução desse processo leva o trabalhador, ao longo do tempo, a diminuir a quantidade de trabalho que executa, bem como a desenvolver reações negativas às pessoas e ao trabalho (Maslach, 2006). Em síntese, essa dimensão do burnout abrange situações em que as pessoas deixam de dar o melhor de si e passam a fazer apenas o estritamente necessário para a sua sobrevivência no trabalho.

O componente de autoavaliação do burnout é representado pela dimensão da diminuição da realização pessoal ou ineficácia, que se refere à sensação de incompetência e à falta de realização e produtividade no trabalho. Essa sensação é diminuída pela autoeficácia e exacerbada pela falta de recursos no trabalho, de apoio social e de oportunidades para o desenvolvimento profissional (Maslach, 2006).

O termo engajamento é empregado por Maslach e Leiter (1997/1999) em contraposição a burnout e considerado por Sousa e Mendonça (2006) como a definição positiva utilizada para forte envolvimento e senso de eficácia, em oposição a exaustão emocional, cinismo e reduzido senso de realização pessoal. 
Burnout é a extremidade de um continuum na relação que as pessoas estabelecem com seu trabalho, aparecendo na outra extremidade o lado positivo do envolvimento do trabalhador com seu trabalho. De acordo com Maslach (2006), as dimensões que representam o envolvimento com o trabalho são: energia, envolvimento e eficácia. Faz-se importante salientar que as estratégias para promover o envolvimento no trabalho podem se apresentar de forma crítica para a prevenção do burnout, assim como para a utilização de estratégias que visam a redução do risco que esta síndrome oferece (Maslach, 2006). No modelo de continuum burnoutenvolvimento de Maslach, que se concentra no ajuste ou na compatibilidade existente entre o trabalhador e seu local de trabalho, quanto maior a compatibilidade, menor a probabilidade do trabalhador desenvolver burnout.

De acordo com a proposta de Maslach (2006), a compatibilidade ou a incompatibilidade entre trabalho e trabalhador mede o ajuste deste indivíduo em seu contexto de trabalho, que é apresentado em seis áreas: carga de trabalho, controle, recompensa, comunidade, justiça organizacional e valores.

Em sua pesquisa sobre as relações entre os valores organizacionais e o burnout, Borges, Argolo e Baker (2006) encontraram associação entre o aumento da incidência da síndrome de burnout e o valor apresentado em nível ideal e real. Observou-se, nesse estudo, que quando as mudanças ocorridas nos valores organizacionais se contrapõem ao aumento da carga de trabalho e salário, há o desenvolvimento da síndrome de burnout. Poderia se dizer que a percepção de injustiça distributiva, nesse contexto, estaria contribuindo para o desenvolvimento do burnout. Conforme Tamayo e Tróccoli (2002a), a percepção de justiça é preditora da síndrome de burnout e, nesse caso, como se trata do aumento da carga de trabalho, trata-se da dimensão distributiva da justiça.

Tamayo e Tróccoli (2002b) investigaram dois aspectos relacionados à exaustão emocional: a percepção de suporte organizacional (PSO) e o fator de escape (coping) no trabalho. Em seu estudo com 369 trabalhadores, esses pesquisadores observaram que tanto os fatores gestão de desempenho, sobrecarga, suporte social e ascensão e salários (PSO) como o fator escape revelaram-se preditores significativos para a ocorrência da dimensão exaustão psicológica. Já para a dimensão percepção de desgaste, só foram significativamente preditivos os fatores suporte social e sobrecarga (PSO). A variável salário também relacionou-se com a exaustão psicológica, o que reforça a importância de entender melhor a percepção de justiça como antecedente ao desenvolvimento do burnout.

Grayson e Alvarez (2008) conduziram pesquisa com o intuito de verificar se o clima (conjunto de valores, atitudes e padrões de comportamento, formais e informais, existentes em uma organização) de 17 escolas rurais localizadas no estado de Ohio, Estados Unidos, e se fatores como traços de personalidade influenciariam o desenvolvimento de burnout entre os professores. Os autores constataram que professores neuróticos e introvertidos estariam mais propícios a desenvolver essa síndrome, bem como aqueles que têm pouco prestígio e atribuem pouco valor a seus alunos. Desse modo, observaram que o relacionamento inverso entre o clima da escola e o burnout foi mediado por níveis de satisfação do professor para as dimensões exaustão emocional e desper- sonalização. Já Kim, Shin e Swanger (2009) encontraram resultados significativos apenas para a relação entre o burnout e a dimensão neurose dos traços de personalidade. Conforme Sabanc1 (2009), o adoecimento do professor pode acarretar o adoecimento da escola. Esses dados demonstram a necessidade de conduzir estudos que busquem compreender modelos mais complexos envolvendo a síndrome de burnout e as variáveis que podem estar relacionadas com o seu desenvolvimento.

\section{A Percepção da (In)Justiça Organizacional e seus Reflexos na Saúde do Trabalhador}

Compreende-se por justiça organizacional aquela aplicada a ambientes organizacionais em que se focam as percepções de justiça que permeiam as relações trabalho-organização (Assmar, Ferreira \& Souto, 2005). Considera-se que para determinar se há justiça, os indivíduos necessitam de um padrão de comparação que pode ser sua própria expectativa, uma pessoa ou um grupo de referência (Kulik \& Ambrose, 1992).

O presente estudo aborda a justiça a partir de uma perspectiva tridimensional, enfocando as percepções de justiça distributiva, processual e interacional.

A justiça distributiva refere-se à alocação de recursos e recompensas. No processo de distribuição de recursos, os critérios ou princípios devem ser claros. Deve haver também uma grande diversidade de posições acerca dos critérios de distribuição de recursos para que o trabalhador perceba a justiça distributiva (Mendonça, 2003).

Deutsch (1985) postula a definição de justiça baseada em três princípios de alocação de recompensas: o da proporcionalidade, o da igualdade e o da necessidade. Conforme o primeiro princípio, as recompensas devem ser distribuídas de acordo com empenho, esforço, ou efetiva participação de cada um em seu trabalho. De acordo com o princípio da igualdade, os ganhos e os prejuízos devem ser distribuídos igualmente. Segundo o princípio das necessidades, os indivíduos devem perceber as recompensas na medida das necessidades pessoais de cada um.

A esses princípios de alocação de recompensas propostos por Deutsch (1985), Paz (1992) acrescentou três outros: o da reciprocidade, o da responsabilidade e o do comprometimento. $\mathrm{O}$ princípio da reciprocidade refere-se à possibilidade de negociação, barganha ou troca de recompensas; o da responsabilidade diz respeito à responsabilidade social do alocador de recompensas em considerar as necessidades e o bem-estar dos recebedores; e o do comprometimento referese às recompensas distribuídas de acordo com a forma de comprometimento dos trabalhadores com o trabalho.

Com o desenvolvimento dos estudos sobre justiça, constatou-se que a dimensão processual sobre as percepções de justiça ou injustiça também é fundamental na dinâmica laboral e refere-se aos procedimentos que levam a uma determinada distribuição de recursos. Os itens desse fator foram definidos com base no pressuposto de que os trabalhadores consideram importante poder opinar e influenciar as decisões organizacionais (Mendonça, Pereira, Tamayo \& Paz, 2003). Também devem ser consideradas as regras enumeradas por 
Leventhal (1980), as quais enfocam a consistência de regras e normas, a ausência de vieses, a veracidade, a coerência, a representatividade, a ética e o recebimento de feedback útil.

Essa dimensão (justiça processual), portanto, engloba os seguintes componentes: (a) controle de voz - refere-se ao direito da pessoa de emitir sua opinião e de ser ouvida em seus diálogos e em suas discussões com os outros; (b) representatividade - refere-se à oportunidade que os trabalhadores têm de possuir representantes nas instâncias superiores da instituição em situações que implicam tomada de decisão envolvendo os interesses de todos os trabalhadores; (c) estabelecimento de critérios - refere-se às decisões tomadas pelas chefias a partir de critérios previamente estabelecidos e acordados entre os trabalhadores; (d) feedback - relativo à preocupação da administração em dar retorno aos funcionários acerca de seu desempenho, seja ele positivo ou negativo, mas sempre útil para a eficácia organizacional; (e) coleta de informações refere-se à preocupação da empresa em conhecer os problemas vivenciados na instituição, sempre coletando informações fidedignas sobre os processos organizacionais.

Por sua vez, a justiça interacional é uma dimensão que diz respeito ao comportamento interpessoal do chefe para com os subordinados, ao modo como os procedimentos são postos em prática (Assmar, Ferreira \& Souto, 2005). De acordo com Bies (1987), as decisões tomadas pelos gerentes, suas ações, a maneira como eles conduzem os procedimentos e explicam suas decisões são decisivos na percepção da existência de justiça.

A percepção de injustiça gera impacto direto no trabalhador, podendo refletir em aspectos físicos, psicológicos e comportamentais. Poucas pesquisas exploraram as implicações da justiça organizacional sobre a saúde dos trabalhadores e os poucos trabalhos que encontraram relação entre justiça e manifestações de desconforto não investigaram os efeitos da injustiça organizacional sobre os índices de tensão psicológica (Tepper, 2001).

Fox e Spector (1999), ao mensurarem as reações afetivas à frustração, encontraram relação positiva entre a percepção de existência de restrições situacionais e comportamentos contraproducentes em resposta a frustrações. Cropanzano e Baron (1991) e Bies (2001) sustentam que a injustiça pode promover emoções que contribuem para a ocorrência de respostas que geram conflito no ambiente organizacional.

Para Elovainio, Kivimäki, Eccles e Sinervo (2002), a percepção de injustiça pode intensificar o estresse ocupacional e comprometer a saúde do trabalhador por três razões: afeta o estresse mediante as relações com os principais preditores psicossociais de sua saúde; desencadeia variações em sua confiança em relação a todos aqueles que tomam decisões importantes para sua vida, além de interferir em sua percepção acerca da qualidade do funcionamento social no contexto do trabalho; e mostra as avaliações dos procedimentos formais e da justiça relacional positivamente (associadas ao ambiente organizacional, aos sentimentos de orgulho e autoestima) e negativamente (relacionadas à raiva, à agressão e ao comportamento social negativo).

Maslach e Leiter (1997/1999) apontam como fator de grande importância para o equilíbrio intrapsíquico do trabalhador a existência da equidade, que gera no trabalhador a percepção de ser reconhecido e valorizado no trabalho.
Isto posto, torna-se fundamental que os trabalhadores, inclusive os professores, sintam-se recompensados de acordo com o que julgam merecer. Assim, cada uma das três dimensões da percepção de justiça (exaustão emocional, despersonalização ou cinismo e diminuição da realização pessoal ou ineficácia) foi estudada nesta pesquisa como variável antecedente à síndrome de burnout, incluindo-se no modelo empírico a mediação do comprometimento afetivo do trabalhador.

\section{Comprometimento Organizacional Afetivo}

O comprometimento organizacional pode ser conceituado como o estado psicológico que caracteriza o vínculo que o trabalhador estabelece com a organização em que atua (Bastos, 1993). A partir dessa definição, presume-se que trabalhadores mais comprometidos teriam menor probabilidade de perceber que estariam sendo injustiçados pela organização, o que os tornaria menos propensos a adoecer, uma vez que quando não existem conflitos internos não há gasto de energia na busca pelo restabelecimento emocional.

Para Mowday, Porter e Steers (1982), apesar de o construto revelar algumas divergências relativas à sua conceituação, o comprometimento afetivo pode ser definido como "força relativa da identificação e envolvimento de um indivíduo com uma organização particular" (p. 27). Oliveira, Lima e Borges-Andrade (1999) corroboram essa definição quando postulam que o enfoque afetivo ou atitudinal está relacionado ao processo de identificação que o trabalhador estabelece com os objetivos e os valores da organização em que está inserido.

O comprometimento afetivo apresenta três aspectos que definem esse construto: os sentimentos de lealdade que envolvem o trabalhador com a organização, ou seja, uma forte crença e aceitação dos objetivos e valores organizacionais; o desejo de permanecer como membro da organização; e uma disposição de esforçar-se em prol da organização (Bastos, 1993; Oliveira \& cols. 1999).

Assim, o comprometimento retrata um comportamento que extrapola a mera lealdade passiva, sendo a representação de uma relação ativa entre a organização e o trabalhador, em que este último está disposto a dar o melhor de si com o intuito de contribuir para o bem-estar organizacional (Oliveira \& cols., 1999). Em outras palavras, o trabalhador realiza-se na identificação com a organização, mantém-se como seu membro e facilita a consecução dos objetivos dela (Bastos, 1993). Percebe-se que o comprometimento afetivo voltado para a organização propicia respostas positivas de satisfação com o trabalho e de autorrealização do trabalhador.

As características do trabalho podem influenciar o comprometimento afetivo do trabalhador para com ele. Destarte, se a organização deixar claro os desafios que o trabalhador deve enfrentar, isto é, se não exigir gastos excessivos de energia com resolução de conflitos que podem levar ao estresse, ele tenderá a comprometer-se mais com a empresa do que ocorreria caso se sentisse inseguro em relação aos desafios que deve enfrentar (Bastos, 2000; Mowday \& cols., 1982).

Vários são os fatores que levam o trabalhador a comprometer-se afetivamente de forma mais intensa com a 
organização, entre os quais se destacam: a percepção de sua importância para a organização; a constatação de que há equidade no pagamento; a percepção da organização de forma positiva por seus colegas; o cumprimento das normas pelo grupo para o desenvolvimento de trabalhos complicados; o fortalecimento dos laços sociais pela organização (Bastos, 2000; Borges-Andrade, Afanasieff \& Silva, 1989; BorgesAndrade, Cameschi \& Silva, 1990; Mowday, Steers \& Porter, 1979; Tamayo, 1998; Tamayo \& cols., 2001). Mowday e cols. (1982) relatam que trabalhadores que lidam com maior formalização, descentralização, dependência funcional e formalidade com as regras tornam-se mais comprometidos afetivamente com seu trabalho.

Rego (2000), Filenga (2003) e Siqueira e Gomide Júnior (2004) conduziram estudos que comprovaram que a percepção de justiça dos procedimentos antecede o comprometimento afetivo e que a percepção de justiça distributiva antecede o comprometimento normativo e calculativo.

Diante do exposto, percebe-se a necessidade de atribuir grau e qualidade à ligação existente entre a organização e o trabalhador, quer seja ela positiva ou negativa. Além disso, devem ser considerados os reflexos dessa ligação para o trabalhador, para a organização e para a sociedade. Portanto, reforça-se a importância do desenvolvimento desta pesquisa ao propor a análise de um modelo mediacional em que o comprometimento afetivo aparece como mediador entre a percepção de justiça e o burnout.

\section{Método}

\section{Participantes}

A presente pesquisa contou com a participação de 233 professores de uma instituição de ensino superior privada, estabelecida na Região Centro-Oeste do Brasil. A amostra foi representada por $52,8 \%$ de indivíduos do gênero feminino e 47,2\% do gênero masculino ( $\mathrm{DP}=0,5)$, com faixa etária variando entre 40 e 49 anos $(\mathrm{M}=43$; $\mathrm{DP}=11,9)$ e vínculo empregatício variando entre 5 e 10 anos $(\mathrm{M}=2,14$; $\mathrm{DP}=$ $1,15)$.

\section{Instrumentos}

Foram utilizadas três escalas de medida para investigar as questões teóricas referentes aos construtos apresentados: Maslach Burnout Inventory (MBI); Escala de Percepção de Justiça Organizacional (EPJO) e Organizational Commitment Questionaire (OCQ).

O MBI foi criado por Maslasch, Jackson e Leiter (1996), e, neste estudo, foi utilizada a versão traduzida por Codo (1999), com algumas adequações para aplicação à população estudada. Esse instrumento é composto de um inventário constituído por 22 itens divididos em três dimensões - exaustão emocional, cinismo e ineficácia, cuja escala de medida varia de 0 (nunca) a 6 (todo dia). Como exemplo das três dimensões, tem-se os itens: "Sinto-me exaurido pelo meu trabalho" - item 8; "Estou preocupado que este trabalho esteja me endurecendo emocionalmente" - item 11; "Consigo finalmente entender como meus alunos se sentem sobre as coisas" - item 4. A análise fatorial do MBI confirmou seus 22 itens distribuídos nas três dimensões - exaustão emocional, $\alpha=0,90$; cinismo, $\alpha=0,79$; e ineficácia, $\alpha=$ 0,71 - e apresentou índice de consistência interna entre as dimensões igual a 0,80 , um valor que está dentro de níveis estatisticamente aceitáveis.

A EPJO, instrumento construído, aferido em sua precisão e validado por Mendonça e cols. (2003), mede a percepção de justiça organizacional em escala que varia de 1 (discordo totalmente) a 5 (concordo totalmente). Também engloba três dimensões - percepção de justiça distributiva, $\alpha=0,91$; percepção de justiça processual, $\alpha=0,90$; e percepção de justiça interacional, $\alpha=0,84-\mathrm{e}$ apresenta coeficientes de fidedignidade aceitos estatisticamente e alto poder taxonômico para mensurar os construtos propostos, dados que foram confirmados neste estudo.

Utilizou-se o OCQ validado no Brasil por BorgesAndrade e cols. (1989), em sua versão reduzida, com escala que varia de 1 (discordo totalmente) a 7 (concordo totalmente), para analisar o comprometimento organizacional afetivo. Trata-se de uma escala unifatorial que neste estudo apresentou $\alpha=0,79$.

\section{Procedimento}

Seguindo todos os procedimentos especificados na Resolução 196/96 do Conselho Nacional de Saúde (CNS) (Ministério da Saúde - Brasil, 1996), esta pesquisa foi submetida e aprovada pelo Conselho de Ética em Pesquisa (CEP; Processo 0178) da Universidade Católica de Goiás.

Os participantes foram devidamente esclarecidos sobre o caráter estritamente acadêmico da pesquisa e a segurança do sigilo em relação à emissão das respostas, após o que assinaram o Termo de Consentimento Livre e Esclarecido. A aplicação dos instrumentos foi feita individualmente na própria instituição de ensino em que trabalham os participantes da pesquisa. Foram entregues 652 conjuntos contendo as três escalas de medida utilizadas na investigação, que não foram identificadas, e um envelope lacrado a ser devolvido com os instrumentos respondidos, dos quais foram devolvidos 233 devidamente respondidos, o que resultou em aproveitamento de $35,73 \%$.

\section{Análise de dados}

O modelo de estudo proposto apresentou uma variável dependente composta por três dimensões - exaustão, cinismo e ineficácia -, uma variável independente composta por três fatores - percepção de justiça distributiva, processual e interacional -, e uma variável mediadora - comprometimento organizacional afetivo.

O efeito mediacional da variável foi interpretado com base na teoria proposta por Baron e Kenny (1986), segundo a qual, para que se analise o efeito mediacional de uma variável é necessário que as seguintes condições sejam obedecidas: a relação entre a variável preditora (VI) e a variável critério 
(VD) deve ser significativa (passo 1); a variável preditora (VI) deve estar relacionada à variável mediadora (VMe) (passo 2); o mediador deve relacionar-se com a variável critério (VD) após o efeito da variável preditora (VI) ter sido controlado (passo 3); a força da associação entre as variáveis preditora (VI) e critério (VD) deve ser reduzida quando o mediador for considerado no modelo (passo 4).

Seguindo essas condições, em um primeiro momento analisou-se a influência da VI (percepção de justiça distributiva, processual e interacional) sobre a VD (burnout em cada dimensão separadamente - exaustão emocional, cinismo e ineficácia). Em seguida, foi feita a regressão incluindo a VI (percepção de justiça distributiva, processual e interacional) sobre a variável mediadora (comprometimento organizacional afetivo). Depois, procedeu-se à análise incluindo todas as variáveis, como a VI (percepção de justiça distributiva, processual e interacional) e a VD (burnout em cada dimensão separadamente - exaustão, cinismo e ineficácia). Finalmente, fez-se um estudo confirmatório do modelo mediacional, pelo teste Sobel, proposto por Baron e Kenny (1986).

\section{Resultados e Discussão}

Para atender ao objetivo de analisar o poder mediacional do comprometimento afetivo na relação entre a percepção de justiça e o burnout, seguiram-se os procedimentos de análise de dados descritos.

Como primeiro passo, realizou-se análise de regressão hierárquica para a dimensão exaustão emocional, a qual revelou $\left[\mathrm{R}=0,51 ; \mathrm{F}_{(2,183)}=32,025 ; \mathrm{p}<0,001\right]$ que a percepção de justiça distributiva $(\beta=-0,41 ; \mathrm{t}=-5,44 ; \mathrm{p}<0,001)$ e a percepção de justiça interacional $(\beta=-0,15 ; \mathrm{t}=-2,05 ; \mathrm{p}<$ $0,05)$ apresentaram-se como suas preditoras (ver Tabela 1).
No entanto, ao introduzir a variável mediadora (comprometimento), a influência da percepção de justiça interacional deixou de ser significativa $(\beta=-0,04 ; \mathrm{t}=-0,45 ; \mathrm{p}=\mathrm{n}$.s. $)$ e a de justiça distributiva teve seu poder de influência diminuído $(\beta=-0,33 ; \mathrm{t}=4,36 ; \mathrm{p}<0,001)$. Apesar de as relações diretas terem diminuído o seu poder de influência ao inserir a variável mediadora, o poder explicativo do modelo de predição da variável exaustão emocional aumentou $\left[\mathrm{R}=0,56 ; \mathrm{F}_{(3,182)}=\right.$ 27,528; $\mathrm{p}<0,001$ ], como pode ser verificado na Tabela 1 .

Esses resultados demonstram que quando o professor é muito comprometido afetivamente com a universidade e se percebe injustiçado pela maneira como os recursos são distribuídos por ela, aumenta-se a probabilidade de que ele desenvolva exaustão emocional. Esse achado é corroborado pelo encontrado por Elovainio e cols. (2001), autores que apontam que a percepção de injustiça pode intensificar o estresse ocupacional e comprometer a saúde do colaborador. Também há concordância com a pesquisa de Tamayo e Tróccoli (2002a), cujos resultados indicam a justiça organizacional como um dos antecedentes do burnout, e o estudo de Maslach (2006), em que este descreve a recompensa insuficiente e a ausência de justiça como causas do desenvolvimento de burnout.

Seguindo os passos para a análise da mediação proposta neste estudo, realizou-se regressão hierárquica para confirmar se as variáveis independentes se configurariam como preditoras da variável mediadora. Os resultados $[\mathrm{R}=0,593$; $\left.\mathrm{F}_{(2,198)}=53,713 ; \mathrm{p}<0,001\right]$ revelaram que tanto a percepção de justiça distributiva $(\beta=0,255 ; \mathrm{t}=3,817 ; \mathrm{p}<0,001)$ quanto a de justiça interacional $(\beta=0,420 ; t=6,289 ; p<0,001)$ foram preditoras do comprometimento organizacional afetivo do professor universitário (Tabela 2).

Esses dados revelam que quanto mais o professor é comprometido afetivamente com a organização, menor é sua probabilidade de desenvolver burnout. Se o professor aceita

Tabela 1. Resultados da regressão hierárquica aplicada à análise do fator mediador 'comprometimento afetivo' entre a percepção de justiça e a exaustão.

\begin{tabular}{|c|c|c|c|c|c|c|}
\hline \multirow{3}{*}{ Variável independente } & \multicolumn{6}{|c|}{ Exaustão } \\
\hline & \multicolumn{3}{|c|}{ Passo 1} & \multicolumn{3}{|c|}{ Passo 3} \\
\hline & Beta & $\mathbf{t}$ & $\mathbf{p}<$ & Beta & $\mathbf{t}$ & $\mathbf{p}<$ \\
\hline \multicolumn{7}{|l|}{ Percepção de justiça } \\
\hline Distributiva & $-0,41$ & $-5,44$ & 0,001 & 0,33 & 4,36 & 0,001 \\
\hline Processual & 0,066 & 0,68 & n.s. & $0,026 \mathrm{c}$ & 0,22 & n.s. \\
\hline Interacional & $-0,15$ & $-2,05$ & 0,05 & $-0,04$ & $-0,45$ & n.s. \\
\hline Comprometimento afetivo & & & & $-0,29$ & $-3,74$ & 0,001 \\
\hline Coeficiente de regressão múltipla & \multicolumn{2}{|c|}{$\mathrm{R}=0,51 ; \mathrm{R}^{2}=0,26$} & & \multicolumn{2}{|c|}{$\mathrm{R}=0,56 ; \mathrm{R}^{2}=0,31$} & \\
\hline Variância explicada & \multicolumn{2}{|c|}{$\mathrm{R}^{2}$ ajustado $=0,25$} & & \multicolumn{2}{|c|}{$\mathrm{R}^{2}$ ajustado $=0,30$} & \\
\hline \multirow[t]{2}{*}{ Teste estatístico } & \multicolumn{2}{|c|}{$\mathrm{F}_{(2,183)}=32,025$} & & \multicolumn{2}{|c|}{$\mathrm{F}_{(3,182)}=27,528$} & \\
\hline & \multicolumn{2}{|c|}{$\mathrm{p}<0,001 \mathrm{~b}$} & & \multicolumn{2}{|c|}{$\mathrm{p}<0,001 \mathrm{c}$} & \\
\hline
\end{tabular}

Nota: A mensuração da variável dependente 'exaustão' foi feita por meio de uma escala de medidas variando de 0 (nunca) a 6 (todo dia); para medir a variável independente 'percepção de justiça' foram atribuídos valores à escala entre 1 (discordo totalmente) e 5 (concordo totalmente); e para mensurar a variável mediadora 'comprometimento afetivo' foi utilizada escala que varia de 1 (discordo totalmente) a 7 (concordo totalmente). 
Tabela 2. Resultados da regressão hierárquica aplicada à análise do fator 'percepção de justiça' e do fator 'comprometimento afetivo'.

\begin{tabular}{|c|c|c|c|}
\hline \multicolumn{4}{|c|}{ Passo 2} \\
\hline \multirow{2}{*}{ Variável independente } & \multicolumn{3}{|c|}{ Comprometimento afetivo } \\
\hline & Beta & $\mathbf{t}$ & $\mathbf{p}<$ \\
\hline \multicolumn{4}{|l|}{ Percepção de justiça } \\
\hline Distributiva & 0,255 & 3,817 & 0,001 \\
\hline Processual & 0,109 & 1,190 & n.s. \\
\hline Interacional & 0,420 & 6,289 & 0,001 \\
\hline Coeficiente de regressão múltipla & \multicolumn{3}{|c|}{$\mathrm{R}=0,593 ; \mathrm{R}^{2}=0,352$} \\
\hline Variância explicada & \multicolumn{3}{|c|}{$\mathrm{R}^{2}$ ajustado $=0,345$} \\
\hline Teste estatístico & \multicolumn{3}{|c|}{$\mathrm{F}_{(2,198)}=53,713 ; \mathrm{p}<0,001$} \\
\hline
\end{tabular}

Nota: Para a mensuração da variável independente 'percepção de justiça' foram atribuídos valores à escala entre 1 (discordo totalmente) e 5 (concordo totalmente); e para medir a variável mediadora 'comprometimento afetivo' foi utilizada escala variando de 1 (discordo totalmente) a 7 (concordo totalmente).

as normas, os valores e os objetivos da organização (Bastos, 1993; Oliveira \& cols., 1999), isso implica satisfação de seus interesses e aumento da vontade de pertencer à organização, não havendo geração de desgaste emocional nesse colaborador, o que resulta em estabilidade emocional geradora de saúde. Conforme postula Maslach (2006), a exaustão é própria dos aspectos mais individualistas, o que explica os aspectos divergentes existentes entre ter comprometimento organizacional (comportamento mais social) e desenvolver exaustão (aspecto mais individual).

Os resultados do presente estudo divergem daqueles relacionados às dimensões da percepção de justiça que Rego (2000), Filenga (2003) e Siqueira e Gomide Júnior (2004) apresentaram. Os autores citados comprovaram que a percepção de justiça dos procedimentos antecede o comprometimento afetivo, enquanto na presente pesquisa as dimensões da percepção de justiça distributiva e interacional apareceram como fatores preditores para o comprometimento afetivo. A ocorrência dessa divergência pode estar relacionada com a amostra deste estudo, composta por professores universitários, ou com a própria realidade do contexto universitário. Esses resultados demonstram que na instituição de ensino superior pesquisada, a alocação de recursos e os relacionamentos interpessoais estão diretamente relacionados com o burnout, e não especificamente o processo decisório.

No tocante ao tratamento de pessoas como se fossem objetos (despersonalização/cinismo), os resultados da regressão $\left[\mathrm{R}=0,201 ; \mathrm{F}_{(1,197)}=8,256 ; \mathrm{p}<0,005\right]$ indicaram que a percepção de justiça interacional $(\beta=0,201 ; \mathrm{t}=-2,87$; $\mathrm{p}$ $<0,005)$ apresentou-se como a principal preditora. No entanto, ao introduzir a variável mediadora comprometimento à equação de regressão, os resultados demonstraram $[\mathrm{R}=$ 0,$\left.268 ; \mathrm{F}_{(2,196)}=7,564 ; \mathrm{p}<0,001\right]$ que a relação entre justiça interacional e cinismo deixou de ser significativa $(\beta=-0,084$; $\mathrm{t}=-1,02 ; \mathrm{p}=$ n.s.).
Os resultados evidenciaram que as percepções de justiça distributiva e processual não se configuraram como preditoras do cinismo e, embora a percepção de justiça interacional pudesse predizer o cinismo, o comprometimento afetivo do professor não atuou como mediador dessa relação.

Em relação à dimensão ineficácia, os resultados da regressão $\left[\mathrm{R}=0,231 ; \mathrm{F}_{(1,189)}=10,634 ; \mathrm{p}<0,001\right]$ indicaram que a percepção de justiça processual $(\beta=0,231 ; \mathrm{t}=-3,26$; $\mathrm{p}<$ $0,001)$ se apresentou como sua única preditora. No entanto, com a introdução da variável mediadora comprometimento, os resultados demonstraram $\left[\mathrm{R}=0,291 ; \mathrm{F}_{(2,188)}=8,667 ; \mathrm{p}<\right.$ $0,001]$ que a relação entre justiça processual e ineficácia deixou de ser significativa. Os dados indicam que as percepções de justiça distributiva e interacional não foram preditoras da ineficácia em uma relação direta, apontando que a percepção de justiça processual pode predizer a ineficácia, mas o comprometimento afetivo do professor não se configurou como variável mediadora dessa relação.

Esses resultados estão de acordo com os obtidos no estudo de Tamayo e Tróccoli (2002b), no qual os autores inserem as variáveis suporte organizacional e coping na relação com a exaustão emocional e percebem que existe relação entre salário e exaustão emocional. Da mesma forma, esses resultados corroboram aqueles relatados por Elovainio e cols. (2002), os quais, embora não tenham utilizado uma escala para medir o burnout em suas três dimensões, confirmaram que a injustiça pode intensificar o estresse ocupacional. E este, no fator psicológico, pode se equiparar teoricamente à dimensão exaustão emocional.

Por outro lado, nota-se a ausência de estudos que relacionem diretamente o burnout em suas três dimensões e a percepção de justiça organizacional também em suas três dimensões, o que reforça a importância deste estudo, que foi desenvolvido focando o modelo mediacional, pois vem confirmar que as relações entre variáveis podem ser mais complexas em suas estruturas.

Para confirmar o modelo mediacional encontrado pela regressão hierárquica, procedeu-se à execução do teste Sobel, proposto por Baron e Kenny (1986). O resultado desse teste confirmou que a mediação do comprometimento afetivo na relação entre a percepção de justiça distributiva e a exaustão emocional foi significativa $(Z=2,63$; $\mathrm{p}<0,01)$.

Como mostrado na Tabela 1 , a percepção de justiça distributiva, em uma relação direta negativa (percepção de injustiça distributiva), exerceu poder preditivo para a variável exaustão. Quando a variável comprometimento organizacional afetivo foi introduzida como mediadora entre a percepção de justiça distributiva e a exaustão, a percepção de injustiça distributiva diminuiu o seu poder de influência sobre a exaustão ao mesmo tempo em que aumentou o poder explicativo da equação.

\section{Considerações Finais}

Para testar o poder mediacional do comprometimento afetivo na relação entre percepção de justiça e burnout, o referencial teórico desta pesquisa articulou construtos psicológicos de grande tradição teórico-metodológica, como teorias sobre a justiça organizacional (Mendonça \& 
cols., 2003), sobre a síndrome de burnout (Maslach, 2006; Tamayo \& Tróccoli, 2002a) e sobre o comprometimento organizacional afetivo (Bastos, 2000). Estudar três grandes temas mostrou-se altamente relevante para compreender as nuanças que permeiam a psicologia organizacional. Dessa forma, a presente pesquisa desvelou o comprometimento organizacional afetivo, demonstrando quão significativo ele é para a minimização de problemas organizacionais ligados à percepção de justiça e ao desenvolvimento do burnout.

A averiguação do valor mediacional do comprometimento organizacional afetivo na relação entre a percepção de justiça e o burnout permitiu constatar que o primeiro só se afirma como mediador na relação entre a percepção de justiça distributiva e a exaustão emocional.

Nossos resultados demonstraram que se o professor se compromete afetivamente com a universidade, a percepção de que está sendo injustiçado na forma de distribuição de recursos provoca o aumento da probabilidade de desenvolvimento da exaustão. Essa ocorre em razão do desgaste energético do professor quando percebe que a organização que ele acreditava lhe ser leal, pois os valores e crenças ali vigentes eram equivalentes aos seus, apresenta atitudes que contradizem essa convicção.

Ao encontrar-se nessa situação, o professor buscará reequilibrar suas energias por meio de justificativas para o comportamento da organização. No entanto, se ele decidir posicionar-se contra a organização, que idealizara perfeita, passará a despender mais energia, o que pode ir gradativamente se acumulando até culminar no desenvolvimento da exaustão. O professor pode, então, se sentir cansado em dar mais do que recebe, exaurindo suas energias por não vislumbrar qualquer possibilidade de mudança. A energia é uma dimensão do envolvimento, uma característica que se refere ao ajuste existente entre o trabalhador e seu local de trabalho, que se contrapõe à dimensão da exaustão, conforme assevera Maslach (2006).

A organização pesquisada vem passando por um processo de reestruturação, de mudanças organizacionais, o que permite compreender, em parte, algumas razões que levaram os professores a perceber em maior grau a injustiça distributiva. Assmar e cols. (2005) destacam que a percepção da injustiça distributiva ocorre, sobretudo, em períodos de reestruturação organizacional, em que "suas consequências diretas acabam sendo restrições de recursos organizacionais aos empregados, sob a forma de redução de incentivos, suspensão de promoções, entre outros" (p. 446).

Na universidade pesquisada, o regulamento de carreira docente não tem sido cumprido, havendo restrições no tocante a promoções por titulação e por tempo de trabalho. Seria interessante que os gestores atentassem para os problemas decorrentes da percepção de injustiça que os professores têm tido acerca da distribuição de recursos e oportunidades. A oferta de recursos e oportunidades acadêmicas, como a obtenção de passagens para participar de congressos e a possibilidade de licença remunerada para alcançar mais um título, traz resultados positivos, enquanto punições, retaliações e falta de oportunidade, na forma de sanções disciplinares e percepção de exclusão do processo, refletem negativamente no desempenho do trabalhador. Não se pode esquecer que a justiça distributiva está ligada aos aspectos mais egoístas do ser humano, que se pauta por motivos econômicos, autointeresse e preocupação em maximizar suas recompensas (Assmar \& cols., 2005).

Os resultados encontrados nesta pesquisa também demonstraram que quanto mais o professor estiver comprometido afetivamente com a organização, menor será a probabilidade de desenvolver exaustão. Portanto, seria interessante que os gestores da universidade estudada repensassem a forma de distribuição de recursos e desenvolvessem estratégias de atuação profissional mais bem aceitas por seu quadro docente. Sugere-se que essas estratégias tenham como meta alcançar padrão de comportamento organizacional voltado para o duplo comprometimento: com a organização e com a profissão (Bastos, 2000). O professor que não se compromete com a organização, provavelmente desenvolverá a exaustão. Por outro lado, o docente que não se compromete com a profissão, dificilmente poderá aprimorar seus conhecimentos ao longo do tempo.

Destaca-se, no entanto, que este estudo apresenta certas limitações, como: ter sido conduzido em uma única instituição, o que impossibilita a generalização para outras, com características e contextos diferentes; ter sido influenciado por outras variáveis na vivência de burnout que não foram contempladas, tais como traços de personalidade (Grayson \& Alvares, 2007; Kim \& cols., 2009); ter se limitado a analisar o fenômeno do burnout a partir de indicadores da percepção do professor sobre a justiça e o comprometimento afetivo; ter encontrado na literatura poucos estudos utilizando as variáveis pesquisadas, o que não permitiu maiores discussões acerca dos resultados encontrados. Porém, nenhuma dessas restrições desmerece a importância desta pesquisa, porquanto ela vem fortalecer a certeza da indispensabilidade de maiores averiguações abarcando esse tema.

A análise relacionada aos dados deste estudo comprova a necessidade de criação e desenvolvimento de políticas de adequação de pessoal para a promoção da saúde dos professores e a prevenção da síndrome de burnout, o que, consequentemente, resultará na saúde da organização.

É importante destacar e reforçar os benefícios de se trabalhar em caráter preventivo, o que traz resultados mais consistentes do que quando apenas se buscam formas de curar/sanar problemas já instalados por falta de priorização de aspectos aqui mencionados. Afinal, como comprovado por esta pesquisa, as avaliações de injustiça podem intensificar o estresse ocupacional e comprometer a saúde do trabalhador (Elovainio \& cols., 2002), o que poderá acarretar adoecimento organizacional (Sabanc1, 2009).

\section{Referências}

Assmar, E. M. L., Ferreira, M. C., \& Souto, S. O. (2005). Justiça organizacional: uma revisão crítica da literatura. Psicologia: Reflexão e Crítica, 18, 443-453.

Baron, R. M., \& Kenny, D. A. (1986). The moderator-mediator variable distinction in social psychological research: Conceptual, strategic, and statistical considerations. Journal of Personality and Social Psychology, 51, 1173-1182. 
Bastos, A. V. B. (1993). Comprometimento organizacional: um balanço dos resultados e desafios que cercam essa tradição de pesquisa. Revista de Administração de Empresas, 33, 52-64.

Bastos, A. V. B. (2000). Padrões de comprometimento com a profissão e a organização: o impacto de fatores pessoais e da natureza do trabalho. Revista de Administração, 35, 48-60.

Bies, R. J. (1987). The predicament of injustice: The management of moral outrage. Em L. L. Cummings \& B. M. Staw (Eds.), Research in organizational behavior, Vol. 9 (pp. 289-319). Greenwich: JAI.

Bies, R. J. (2001). International (in)justice: The sacred and the profane. Em J. Greenberg \& R. Cropanzano (Orgs.), Advances in organizational justice (pp. 89-118). Stanford: Stanford University.

Borges-Andrade, J. E., Afanasieff, R. S., \& Silva, M. S. (1989). Mensuração de comprometimento organizacional em instituições públicas [Resumo]. Em Sociedade Brasileira de Psicologia (Org.), Resumos da XIX Reunião Anual de Psicologia (p. 236). Ribeirão Preto: SBP.

Borges-Andrade, J. E., Cameschi, C. E., \& Silva, M. S. (1990). Comprometimento organizacional em instituição de pesquisa: diferenças entre meio e fim. Revista de Administração, 25, 29-43.

Borges, L. de O., Argolo, J. C. T., \& Baker, M. C. S. (2006). Os valores organizacionais e a síndrome de burnout: dois momentos em uma maternidade pública. Psicologia: Reflexão \& Crítica, 19, 34-43.

Carlotto, M. S., \& Câmara, S. G. (2008). Análise da produção científica sobre a Síndrome de Burnout no Brasil. Psico, 39, 152158

Carlotto, M. S., \& Palazzo, L. S. (2006). Síndrome de burnout e fatores associados: um estudo epidemiológico com professores. Cadernos de Saúde Pública, 22, 1017-1026.

Codo, W. (1999). Educação: carinho e trabalho. Petrópolis: Vozes.

Codo, W., \& Vasques-Menezes, I. (2000). Burnout: sofrimento psíquico dos trabalhadores em educação. Cadernos de Saúde do Trabalhador, 14, 29-48.

Cropanzano, R., \& Baron, R. A. (1991). Injustice and organizational conflict: The moderating role of power restoration. International Journal of Conflict Management, 2, 5-26.

Deutsch, M. (1985). Distributive justice: A social-psychological perspective. New Haven: Yale University.

Elovainio, M., Kivimäki, M., Eccles, M., \& Sinervo, T. (2002). Team climate and procedural justice as predictors of occupational strain. Journal of Applied Social Psychology, 32, 359-372.

Filenga, D. (2003). O impacto de percepções de justiça em três bases de comprometimento organizacional [Resumo]. Em Associação Nacional de Pós-Graduação e Pesquisa em Administração (Org.), XXVII Encontro da ANPAD. Rio de Janeiro: ANPAD, CD-ROM.

Fox, S., \& Spector, P. E. (1999). A model of work frustrationaggression. Journal of Organizational Behavior, 20, 915-931.

Grayson, J. L., \& Alvarez, H. K. (2008). School climate factors relating to teacher burnout: A mediator model. Teaching and Teacher Education: An International Journal of Research and Studies, 24, 1349-1363.

Kim, H. J., Shin, K. H., \& Swanger, N. (2009). Burnout and engagement: A comparative analysis using the big five personality dimensions. International Journal of Hospitality Management, 28, 96-104.
Kulik, C. T., \& Ambrose, M. L. (1992). Personal and situational determinants of referent choice. Academy of Management Review, 17, 212-237.

Leventhal, G. S. (1980). What should be done with equity theory? Em K. J. Gergen, M. S. Greenberg \& R. H. Willis (Eds.), Social exchange: Advances in theory and research (pp. 27-55). New York: Plenum.

Maslach, C. (2006). Promovendo o envolvimento e reduzindo o burnout [Resumo]. Em International Stress Management Association (Org.), Anais do VI Congresso de Stress da ISMA-BR, VIII Fórum Internacional de Qualidade de Vida no Trabalho. Porto Alegre: ISMA, CD-ROM.

Maslach, C., \& Jackson, S. E. (1981). The measurement of experienced burnout. Journal of Occupational Behaviour, 2, 99-113.

Maslach, C. P., Jackson, S. E., \& Leiter, M. P. (1996). Maslach Burnout Inventory Manual ( $3^{\mathrm{a}}$ ed.). Palo Alto: Consulting Psychologist Press.

Maslach, C., \& Leiter, P. M. (1999). Trabalho: fonte de prazer ou desgaste? Guia para vencer o estresse na empresa (M. S. Martins, Trad.). Campinas: Papirus. (Trabalho original publicado em 1997)

Mendonça, H. (2003). Retaliação organizacional: o impacto dos valores e da justiça. Tese de Doutorado, Universidade de Brasília, Brasília.

Mendonça, H., Pereira, C., Tamayo, A., \& Paz, M. G. T. (2003). Validação fatorial de uma escala de percepção de justiça organizacional. Estudos, Vida e Saúde, 30, 111-130.

Ministério da Saúde - Brasil (1996). Resolução $n^{\circ}$ 196/96 Conselho Nacional de Saúde (CNS). Brasília: Diário Oficial da União.

Monteiro, Z. H. M. (2000). Desempenho escolar, condições de trabalho e as implicações para a saúde do professor. Dissertação de Mestrado, Universidade do Estado do Rio de Janeiro, Rio de Janeiro.

Mowday, R. T., Porter, L. W., \& Steers, R. M. (1982). Employeeorganization linkages: The psychology of commitment, absenteeism, and turnover. New York: Academic Press.

Mowday, R. T., Steers, R. M., \& Porter, L. W. (1979). The measurement of organizational commitment. Journal of Vocational Behavior, 14, 224-247.

Oliveira, M. A. P. S., Lima, S. M. V., \& Borges-Andrade, J. E. (1999). Comprometimento no trabalho e produção científica entre pesquisadores brasileiros. Revista de Administração, 34, 12-20.

Paz, M. G. T. (1992). Justiça distributiva na avaliação de desempenho dos trabalhadores de uma empresa estatal. Tese de Doutorado, Universidade de São Paulo, São Paulo.

Rego, A. (2000). Comportamentos de cidadania organizacional - uma abordagem empírica a alguns dos seus antecedentes e conseqüências. Tese de Doutorado, Instituto Superior de Ciências do Trabalho e da Empresa, Lisboa.

Sabanc1, A. (2009). The effect of primary school teachers' burnout on organizational health [Abstract]. Em Uzunboylu, H. (Org.), I World Conference on Educational Sciences (p. 195-205). Nicosia: Cyprus Education Sciences Association, World Education, Science, Research and Councilling Center.

Siqueira, M. M. M., \& Gomide Júnior, S. (2004). Vínculos do indivíduo com o trabalho e com a organização. Em J. C. Zanelli, J. E. Borges-Andrade \& A. V. B. Bastos. (Orgs.), Psicologias, organização e trabalho no Brasil (pp. 300-328). Porto Alegre: Artmed. 
Sousa, I. F., \& Mendonça, H. (2006). Do stress ao burnout: a mediação das estratégias de coping [Resumo]. Em International Stress Management Association (Org.), Anais do VI Congresso de Stress da ISMA-BR, VIII Fórum Internacional de Qualidade de Vida no Trabalho. Porto Alegre: ISMA. CD-ROM.

Tamayo, A. (1998). Valores organizacionais: sua relação com satisfação no trabalho, cidadania organizacional e comprometimento afetivo. Revista de Administração, 33, 56-63.

Tamayo, A., Souza, M. G. S., Vilar, S. L., Ramos, J. L., Albernaz, J. V., \& Ferreira, N. P. (2001). Prioridades axiológicas e comprometimento organizacional. Psicologia: Teoria e Pesquisa, 17, 27-35.

Tamayo, M. R., \& Tróccoli, B. T. (2002a). Burnout no trabalho. Em A. M. Mendes, L. O. Borges \& M. C. Ferreira (Orgs.), Trabalho em transição, saúde em risco (pp. 43-58). Brasília: Universidade de Brasília.
Tamayo, M. R., \& Tróccoli, B. T. (2002b). Exaustão emocional: relações com a percepção de suporte organizacional e com as estratégias de coping no trabalho. Estudos de Psicologia, 7, 3746.

Tepper, B. J. (2001). Health consequences of organizational injustice and interactive effects: tests of main and interactive effects. Organizational Behavior and Human Decision Processes, 2, 197-215.
Recebido em 31.08.07

Primeira decisão editorial em 20.04.09

Versão final em 07.05.09

Aceito em 06.06.09 